\title{
Osteosarcoma of the spine: prognostic variables for local recurrence and overall survival, a multicenter ambispective study
}

\author{
${ }^{*}$ Mark B. Dekutoski, MD, ${ }^{1}$ Michelle J. Clarke, MD, ${ }^{2}$ Peter Rose, MD, ${ }^{3}$ Alessandro Luzzati, MD, ${ }^{4}$ \\ Laurence D. Rhines, MD, ${ }^{5}$ Peter P. Varga, MD, ${ }^{6}$ Charles G. Fisher, MD, MHSc, FRCSC, ${ }^{7}$ \\ Dean Chou, MD, ${ }^{8}$ Michael G. Fehlings, MD, PhD, FRCSC, ${ }^{9}$ Jeremy J. Reynolds, FRCS, ${ }^{10}$ \\ Richard Williams, FRACS,11 Nasir A. Quraishi, FRCS,12 Niccole M. Germscheid, MSc, ${ }^{13}$ \\ Daniel M. Sciubba, MD, ${ }^{14}$ Ziya L. Gokaslan, MD, ${ }^{15}$ Stefano Boriani, MD, ${ }^{16}$ and the AOSpine \\ Knowledge Forum Tumor
}

${ }^{1}$ Department of Orthopedics, CORE Institute, Phoenix, Arizona; Departments of ${ }^{2}$ Neurologic Surgery and ${ }^{3}$ Orthopedics, Mayo Clinic, Rochester, Minnesota; ${ }^{4}$ Oncologia Ortopedica e Ricostruttiva del Rachide, Istituto Ortopedico Galeazzi, Milan, Italy; ${ }^{5}$ Department of Neurosurgery, The University of Texas MD Anderson Cancer Center, Houston, Texas; ${ }^{6}$ National Center for Spinal Disorders and Buda Health Center, Budapest, Hungary; ${ }^{7}$ Division of Spine, Department of Orthopaedics, University of British Columbia and Vancouver Coastal Health, Vancouver, British Columbia, Canada; ${ }^{8}$ Department of Neurological Surgery, University of California, San Francisco, California; ${ }^{D}$ Division of Neurosurgery, Department of Surgery, University of Toronto and Toronto Western Hospital, Toronto, Ontario, Canada; ${ }^{10}$ Spinal Division, Oxford University Hospitals NHS Trust, Oxford, United Kingdom; ${ }^{11}$ Department of Orthopaedics, Princess Alexandra Hospital, Brisbane, Queensland, Australia; ${ }^{12}$ Center for Spine Studies and Surgery, Queens Medical Centre, Nottingham University Hospitals NHS Trust, Nottingham, United Kingdom; ${ }^{13}$ Research Department, AOSpine International, Davos, Switzerland; ${ }^{14}$ Department of Neurosurgery, Johns Hopkins University School of Medicine, Baltimore, Maryland; ${ }^{15}$ Department of Neurosurgery, The Warren Alpert Medical School of Brown University, Providence, Rhode Island; and ${ }^{16}$ Unit of Oncologic and Degenerative Spine Surgery, Rizzoli Institute, Bologna, Italy

OBJECTIVE Primary spinal osteosarcomas are rare and aggressive neoplasms. Poor outcomes can occur, as obtaining marginal margins is technically demanding; further Enneking-appropriate en bloc resection can have significant morbidity. The goal of this study is to identify prognostic variables for local recurrence and mortality in surgically treated patients diagnosed with a primary osteosarcoma of the spine.

METHODS A multicenter ambispective database of surgically treated patients with primary spine osteosarcomas was developed by AOSpine Knowledge Forum Tumor. Patient demographic, diagnosis, treatment, perioperative morbidity, local recurrence, and cross-sectional survival data were collected. Tumors were classified in 2 cohorts: Enneking appropriate (EA) and Enneking inappropriate (EI), as defined by pathology margin matching Enneking-recommended surgical margins. Prognostic variables were analyzed in reference to local recurrence and survival.

RESULTS Between 1987 and 2012, 58 patients (32 female patients) underwent surgical treatment for primary spinal osteosarcoma. Patients were followed for a mean period of $3.5 \pm 3.5$ years (range 0.5 days to 14.3 years). The median survival for the entire cohort was 6.7 years postoperative. Twenty-four (41\%) patients died, and 17 (30\%) patients suffered a local recurrence, 10 (59\%) of whom died. Twenty-nine (53\%) patients underwent EA resection while $26(47 \%)$ patients underwent El resection with a postoperative median survival of 6.8 and 3.7 years, respectively $(p=0.048)$. El patients had a higher rate of local recurrence than EA patients $(p=0.001)$. Patient age, previous surgery, biopsy type, tumor size, spine level, and chemotherapy timing did not significantly influence recurrence and survival.

CONCLUSIONS Osteosarcoma of the spine presents a significant challenge, and most patients die in spite of aggressive surgery. There is a significant decrease in recurrence and an increase in survival with en bloc resection (EA) when

ABBREVIATIONS EA = Enneking appropriate; EI = Enneking inappropriate. SUBMITTED July 21, 2015. ACCEPTED November 20, 2015.

INCLUDE WHEN CITING Published online March 4, 2016; DOI: 10.3171/2015.11.SPINE15870.

* Drs. Dekutoski and Clarke contributed equally to this work. 
compared with intralesional resection (EI). The effect of adjuvant and neoadjuvant chemotherapeutics, as well as method of biopsy, requires further exploration.

http://thejns.org/doi/abs/10.3171/2015.11.SPINE15870

KEY WORDS osteosarcoma; spine; primary tumor; en bloc resection; neoadjuvant chemotherapy; surgery; tumor; survival; oncology

A LTHOUGH osteosarcoma is the most common primary malignant bone tumor, only $3 \%-5 \%$ of cases occur in the spine. $1,21,32,52,55,59,62$ Due to the low incidence, treatment paradigms have been based on small series and case reports ${ }^{1,51,52,57,58}$ and by extrapolating data from larger appendicular series. ${ }^{28,37,39,49,51,55}$ As originally outlined by Enneking et al., musculoskeletal sarcoma is best treated with wide resection and adjuvant therapies where histologically appropriate. ${ }^{3}$ Thus, it is currently believed that multimodality therapy, including adjuvant or neoadjuvant chemotherapy and surgery, is the most effective treatment for primary osteosarcoma of the spine. ${ }^{3,19,44,48,56}$ However, despite aggressive treatment, historically survival has been poor. ${ }^{44,51,55}$

The primary goal of the surgical treatment of spinal sarcomas is curative resection with negative margins. Depending on the size and location of the tumor, achieving this oncological goal may result in significant patient morbidity. In multiple case reports and mixed histology studies, aggressive resection improves neurological and functional status and may extend survival. 2,4,5,9,25,27,34,35,38,43,58 However, in the vast majority of these older studies, palliative intralesional resections were performed. In contrast, treating extraspinal sarcomas with en bloc resections and wide or marginal negative margins has improved local tumor control and long-term survival. 8,17,20,24,30,31,33,41,47,50,53,54,63 Beginning with Tomita, advances in spinal surgery have enabled en bloc resection of spinal column tumors throughout the fixed and mobile spine. ${ }^{12-16,45,46,60,61,65}$

Similar to extraspinal surgery, the terminology for surgical staging, extent of resection, and grading of margins can be applied. The Enneking classification was originally intended for appendicular tumors ${ }^{22,23}$ and predicts prognosis based on surgical margins. Although anatomical considerations in the spine make direct application difficult, it is possible to classify resections as Enneking appropriate (EA) or Enneking inappropriate (EI) based on the surgical margins. To account for the complexity of spine anatomy, the Weinstein-Boriani-Biagini classification system was developed. ${ }^{7}$ These systems have been validated and are considered feasible to apply to primary spine tumor surgery in order to optimize patient care and research reliability. , $^{6,26}$

The aim of this study is to identify the prognostic variables for recurrence and survival in surgically treated patients suffering from primary osteosarcomas of the spine using ambispectively collected multiinstitutional data. Specifically, the impact of EA and EI resections using contemporary surgical techniques and the use of neoadjuvant chemotherapy are explored.

\section{Methods Design}

An international, multicenter, retrospective review of prospectively collected data or ambispective design with cross-sectional follow-up was conducted. Ethics board approval was received by each participating spine center. Twelve spine oncology referral centers from 3 geographic regions contributed data. The patients included in this study had a diagnosis of primary osteosarcoma of the spine, underwent surgical intervention at one of the participating spine centers between March 1987 and April 2012, and received regular surgical follow-up. Patients were excluded if they were admitted for the treatment of a metastatic spinal tumor or if they were diagnosed with a primary spinal cord tumor.

Demographic data, tumor histology, final pathological resection margins, Enneking stage, ${ }^{23}$ chemotherapy and radiation therapy timing, local recurrence, and survival data were collected from the clinical charts and institutional databases. Whenever necessary, governmental databases were accessed to retrieve data concerning survival. A secure Web-based application (REDCap, Vanderbilt University) was used to store and manage the aggregated data.

Patients were analyzed in 2 groups: EA or EI. For osteosarcomas, wide or marginal margins are recommended by the Enneking criteria. If this was achieved, surgery was EA, and if this was not achieved, surgery was EI. Of note, patients who underwent a previous surgery for their sarcoma and the resection was previously described as being intralesional were also considered to be EI.

\section{Surgical Technique}

A range of surgeon preferences and differences in tumor location, size, and aggressiveness of the tumors lead to different surgical techniques being carried out (Table 1). Some centers strictly followed the Enneking principles, while others did not. Sometimes the proximity of critical anatomy and extent of tumor prevented the recommended margins.

\section{Pathological Results}

The final results for the EA or EI margins and tumor grade were based on the pathological evaluation of the surgical specimen, which was performed by an experienced musculoskeletal pathologist. The Enneking classification distinguishes between wide and marginal resections, yet due to the complex anatomy of the mobile spine, these 2 
TABLE 1. Summary of the treatment details

\begin{tabular}{|c|c|}
\hline Variable & No. of Patients (\%) \\
\hline \multicolumn{2}{|c|}{ Preoperative embolization $(n=51)$} \\
\hline No & $39(76)$ \\
\hline Yes & $12(24)$ \\
\hline \multicolumn{2}{|l|}{ Surgical approach $(n=58)$} \\
\hline Posterior & $19(33)$ \\
\hline Anterior/posterior & $19(33)$ \\
\hline Posterior/anterior & $7(12)$ \\
\hline Posterior/anterior/posterior & $4(7)$ \\
\hline Other & $9(16)$ \\
\hline \multicolumn{2}{|c|}{ Pathological results of surgical specimen $(n=54)$} \\
\hline Wide or marginal & $34(63)$ \\
\hline Intralesional & $20(37)$ \\
\hline \multicolumn{2}{|l|}{ Fixation used $(n=57)$} \\
\hline Posterior & $37(65)$ \\
\hline Both & $8(14)$ \\
\hline None & $12(21)$ \\
\hline \multicolumn{2}{|l|}{ Reconstruction $(n=56)$} \\
\hline No & $20(36)$ \\
\hline Yes* $^{*}$ & $36(64)$ \\
\hline Autograft & $17(33)$ \\
\hline Allograft & $9(17)$ \\
\hline Titanium cage & $11(21)$ \\
\hline Carbon fiber cage & $12(23)$ \\
\hline Vascular autograft & $2(4)$ \\
\hline Cement & $1(2)$ \\
\hline \multicolumn{2}{|c|}{ Enneking appropriateness $(n=55)$} \\
\hline EA & $29(53)$ \\
\hline El & $26(47)$ \\
\hline \multicolumn{2}{|l|}{ Chemotherapy timing $(n=58)$} \\
\hline Preoperative & $19(33)$ \\
\hline Postoperative & $9(16)$ \\
\hline Both & $19(33)$ \\
\hline None & $11(19)$ \\
\hline \multicolumn{2}{|l|}{ Radiation therapy timing $(n=58)$} \\
\hline Preoperative & $9(16)$ \\
\hline Postoperative & $15(26)$ \\
\hline None & $34(59)$ \\
\hline
\end{tabular}

* The same patient can contribute to more than 1 category.

categories were combined into 1 category because sparing the dura from marginal resection is generally preferred over a wide resection (which includes the dura as a margin), except possibly in the setting of sacral amputation.

\section{Treatment}

In addition to surgical treatment, multidisciplinary teams, which included medical and radiation oncologists, consulted patients both pre- and postoperatively to determine the need for adjuvant and neoadjuvant chemotherapy and radiation therapy. Similar to the surgical techniques, treatment was center and patient dependent.

\section{Statistical Analysis}

Descriptive statistics, such as the mean, standard deviation, percentage, and frequency, were used to summarize the demographic data. For differences between groups, the chi-square tests (Pearson's and Fisher's exact tests, as appropriate) were used for categorical variables, and the Student t-test and Mann-Whitney test, as appropriate, for continuous variables. Univariate analysis, which used Kaplan-Meier survival curves and log-rank tests, was performed over a 10-year period postoperatively to identify factors that potentially influenced local recurrence and mortality. Statistical significance was decided when $\mathrm{p} \leq$ 0.05. All statistical analyses were performed using STATA (version 12.0).

\section{Results}

A total of 58 patients with a mean age of 36.0 years (range 11.3-76.4 years) received surgical treatment for a primary spinal osteosarcoma (Table 2). Thirty-two (55\%) patients were female, and $26(45 \%)$ patients were male. Pain was reported in $52(95 \%)$ patients. Fifteen (26\%) patients had a previous spine tumor operation, and 12 (21\%) of these were reported as intralesional resections that resulted in an EI procedure. A histological diagnosis by CT-trocar biopsy was made in $30(61 \%)$ patients. Most lesions were located in the mobile spine $(\mathrm{n}=41 ; 71 \%)$. Almost every patient presented with a high-grade lesion (n $=53 ; 96 \%)$ and most spanned more than 1 vertebra $(\mathrm{n}=$ $48 ; 83 \%$ ) (Table 3). The mean tumor size was known in 52 patients in 3 dimensions: anterior-posterior $(7.9 \pm 4.8 \mathrm{~cm})$; left-right $(7.4 \pm 4.9 \mathrm{~cm})$; and cephalad-caudad $(7.1 \pm 5.9$ $\mathrm{cm})$. Patients were followed for a mean period of $3.5 \pm 3.5$ years, spanning a maximum of 14.3 years. Data concerning the metastatic disease status were not collected.

\section{Treatment}

Fifty-one patients reported preoperative embolization, with 12 of these (24\%) receiving treatment (Table 1$)$. The 2 most common surgical approaches were posterior $(\mathrm{n}=$ $19 ; 33 \%)$ and anterior/posterior $(\mathrm{n}=19 ; 33 \%)$. Fixation was used in $45(79 \%)$ patients. Twenty $(36 \%)$ patients did not receive spine reconstruction, most likely because neoplastic and iatrogenic effects were not mechanically significant. In addition to surgical treatment, 47 (81\%) patients received chemotherapy and $24(41 \%)$ patients received radiation therapy. Data about the Enneking appropriateness of surgery were available for 55 patients: 29 (53\%) patients received an EA procedure and 26 (47\%) received an EI procedure. The distribution of the study variables according to Enneking appropriateness is shown in Table 4. None of the EA-treated patients underwent a previous spine tumor surgery $(\mathrm{p}<0.001)$. The type of biopsy differed between EA- and EI-treated patients $(p=0.001)$. The majority of patients who received an EA procedure $(\mathrm{n}=$ $20 ; 80 \%$ ) also received CT-trocar biopsies, while only 8 (38\%) EI-treated patients received CT-trocar biopsies. The tumor volume was larger in EA-treated patients compared with EI-treated patients $(\mathrm{p}=0.007)$. In total, 24 of 29 (83\%) EA-treated patients received neoadjuvant chemotherapy compared with 13 of $26(50 \%)$ EI-treated patients 
TABLE 2. Summary of the patient clinical characteristics*

\begin{tabular}{|c|c|}
\hline Variable & Value \\
\hline Mean age at surgery in yrs $(n=58)$ & $36.0 \pm 16.1$ \\
\hline \multicolumn{2}{|l|}{$\operatorname{Sex}(n=58)$} \\
\hline Female & $32(55)$ \\
\hline Male & $26(45)$ \\
\hline \multicolumn{2}{|l|}{ Pain at diagnosis $(n=55)$} \\
\hline No & $3(5)$ \\
\hline Yes & $52(95)$ \\
\hline \multicolumn{2}{|c|}{ Pathological fracture at diagnosis $(n=56)$} \\
\hline No & $44(79)$ \\
\hline Yes & $12(21)$ \\
\hline \multicolumn{2}{|l|}{ Previous spine tumor operation $(n=58)$} \\
\hline No & $43(74)$ \\
\hline Yes & $15(26)$ \\
\hline \multicolumn{2}{|l|}{ Biopsy $(n=49)$} \\
\hline Open & $11(22)$ \\
\hline CT-trocar & $30(61)$ \\
\hline Intraoperative & $8(16)$ \\
\hline \multicolumn{2}{|c|}{ Preoperative Frankel/ASIA grade $(n=52)$} \\
\hline A & $1(2)$ \\
\hline $\mathrm{B}$ & $1(2)$ \\
\hline C & $6(12)$ \\
\hline D & $14(27)$ \\
\hline$E$ & $30(58)$ \\
\hline \multicolumn{2}{|l|}{ Spine level $(n=58)$} \\
\hline Mobile & $41(71)$ \\
\hline Fixed & $17(29)$ \\
\hline \multicolumn{2}{|l|}{ Local recurrence $(n=57)$} \\
\hline No & $40(70)$ \\
\hline Yes & $17(30)$ \\
\hline \multicolumn{2}{|l|}{ Survival $(n=58)$} \\
\hline Alive & $34(59)$ \\
\hline Dead & $24(41)$ \\
\hline
\end{tabular}

ASIA = American Spinal Injury Association.

* Data are presented as number of patients (\%) or mean \pm standard deviation.

$(p=0.035)$. Statistical differences were not found between Enneking cohorts when comparing the other baseline characteristics such as age at surgery $(\mathrm{p}=0.749)$, sex $(\mathrm{p}=$ $0.875)$, spine level $(p=0.234)$, number of vertebral levels spanned by the tumor $(\mathrm{p}=0.128)$, timing of chemotherapy $(\mathrm{p}=0.062)$, and timing of radiation therapy $(\mathrm{p}=0.740)$.

\section{Local Recurrence}

During the study period, 17 (30\%) patients developed a local recurrence, 10 of whom later died. Local recurrence information was unknown for 1 patient because the patient had already died. The median time to first local recurrence for all patients was not reached during the analysis. Considering only those patients for whom we have data available for Enneking appropriateness, 3 (10\%) EA patients and 11 (44\%) EI patients developed a local recurrence (Table 4). The Kaplan-Meier analysis conducted
TABLE 3. Summary of the osteosarcoma characteristics

\begin{tabular}{|c|c|}
\hline Variable & Value $^{*}$ \\
\hline \multicolumn{2}{|l|}{ Enneking stage $(n=55)$} \\
\hline Low grade (I) & $2(4)$ \\
\hline Intracompartmental (la) & $0(0)$ \\
\hline Extracompartmental (lb) & $2(100)$ \\
\hline High grade (II) & $53(96)$ \\
\hline Intracompartmental (Ila) & $1(2)$ \\
\hline Extracompartmental (Ilb) & $52(98)$ \\
\hline \multicolumn{2}{|c|}{ No. of vertebral levels spanned by the tumor $(n=58)$} \\
\hline 1 & $10(17)$ \\
\hline $2-3$ & $30(52)$ \\
\hline$\geq 4$ & $18(31)$ \\
\hline \multicolumn{2}{|l|}{ Mean tumor size in $\mathrm{cm}(n=52)$} \\
\hline Anterior-posterior & $7.9 \pm 4.8$ \\
\hline Left-right & $7.4 \pm 4.9$ \\
\hline Cephalad-caudad & $7.1 \pm 5.9$ \\
\hline Mean tumor vol ellipsoid body in $\mathrm{cm}^{3}(n=51) \dagger$ & $473.1 \pm 978.4$ \\
\hline
\end{tabular}

over a 10-year period following surgical resection demonstrated a significant difference between the 2 Enneking procedures, and the EI procedure has a higher rate of local recurrence $(p=0.001$; Fig. 1$)$. There were no other statistical differences found on the univariate analysis when evaluating the rate of local recurrence, including the use of adjuvant or neoadjuvant chemotherapy (Table 5).

\section{Survival}

Twenty-four (41\%) patients died during the study period. The median survival of all patients was 6.7 years postoperatively. Considering only those patients for whom we have data available for Enneking appropriateness, 9 (31\%) EA patients and $13(50 \%)$ EI patients died (Table 4). The Kaplan-Meier analysis conducted over a 10 -year period following resection demonstrated a significant difference in favor of greater survival following EA treatment $(\mathrm{p}=$ 0.048) (Fig. 2). There were no other statistical differences found when evaluating patient survival on the univariate analysis (Table 5).

\section{Discussion}

Osteosarcoma of the spine is a rare but aggressive tumor with a poor prognosis. Recent advances in treatment, including aggressive en bloc resection and the use of adjuvant and neoadjuvant chemotherapeutics, trend toward longer survival times and less recurrence, although the data are limited. This study is the largest collection of spinal osteosarcomas studied to date, and the only ambispective and multicenter data set available.

Consistent with previous studies, these data continue to demonstrate that spinal osteosarcoma is a sinister diagnosis. In this study, $30 \%$ of patients suffered recurrence and $41 \%$ of patients died by the final follow-up. However, these numbers reflect an improvement over previous sur- 
TABLE 4. Comparison of Enneking cohorts*

\begin{tabular}{|c|c|c|c|}
\hline Variable & EA & El & $\mathrm{p}$ Value \\
\hline Mean age at surgery $(y r s)(n=55)$ & $36.6 \pm 15.5$ & $35.2 \pm 17.0$ & $0.749 \dagger$ \\
\hline $\operatorname{Sex}(n=55)$ & & & $0.875 \ddagger$ \\
\hline Female & $15(52)$ & $14(54)$ & \\
\hline Male & $14(48)$ & $12(46)$ & \\
\hline Previous spine tumor operation $(n=55)$ & & & $<0.001 \S$ \\
\hline Yes & $0(0)$ & $14(54)$ & \\
\hline No & $29(100)$ & $12(46)$ & \\
\hline Biopsy $(n=46)$ & & & $0.001 \S$ \\
\hline Open & $5(20)$ & $5(24)$ & \\
\hline CT-trocar & $20(80)$ & $8(38)$ & \\
\hline Intraoperative & $0(0)$ & $8(38)$ & \\
\hline Spine level $(n=55)$ & & & $0.234 \ddagger$ \\
\hline Mobile & $18(62)$ & $20(77)$ & \\
\hline Fixed & $11(38)$ & $6(23)$ & \\
\hline No. of vertebral levels spanned by the tumor $(n=55)$ & & & $0.128 \S$ \\
\hline 1 & $4(14)$ & $5(19)$ & \\
\hline $2-3$ & $12(41)$ & $16(62)$ & \\
\hline$\geq 4$ & $13(45)$ & $5(19)$ & \\
\hline Tumor vol ellipsoid body $\left(\mathrm{cm}^{3}\right)(n=50)^{* *}$ & IQR 58.3-675.2 & IQR 16.8-175.9 & $0.007 \rrbracket$ \\
\hline Chemotherapy timing $(n=55)$ & & & $0.062 \S$ \\
\hline Preoperative & $11(38)$ & $8(31)$ & \\
\hline Postoperative & $2(7)$ & $6(23)$ & \\
\hline Both & $13(45)$ & $5(19)$ & \\
\hline None & $3(10)$ & $7(27)$ & \\
\hline Radiation therapy timing $(n=55)$ & & & $0.740 \S$ \\
\hline Preoperative & $5(17)$ & $4(15)$ & \\
\hline Postoperative & $5(17)$ & $7(27)$ & \\
\hline None & $19(66)$ & $15(58)$ & \\
\hline Local recurrence $(n=54)$ & & & $0.011 \S$ \\
\hline No & $26(90)$ & $14(56)$ & \\
\hline Yes & $3(10)$ & $11(44)$ & \\
\hline Survival $(n=55)$ & & & $0.152 \ddagger$ \\
\hline Alive & $20(69)$ & $13(50)$ & \\
\hline Dead & $9(31)$ & $13(50)$ & \\
\hline \multicolumn{4}{|c|}{$\begin{array}{l}\text { IQR }=\text { interquartile range. } \\
\text { * Data are presented as number }(\%) \text {, mean } \pm \text { standard deviation, or interquartile range }(25-75 \text { th percentile). } \\
\text { † Determined using the Student } t \text {-test. } \\
\text { † Determined using the Pearson's chi-square test. } \\
\S \text { Determined using the Fisher's exact test. } \\
\text { I Determined using the Mann-Whitney test. } \\
* \text { Tumor volume ellipsoid body }=\pi / 6 \times \text { height } \times \text { width } \times \text { depth. }\end{array}$} \\
\hline
\end{tabular}

vival rates ${ }^{51,55}$ Likely, this reflects both the addition of aggressive resection and chemotherapeutics to the treatment armamentarium and parallels improvements in survival when these tools were applied to patients suffering from appendicular osteosarcomas. ${ }^{38,49,51,55}$ Additionally, as this cohort includes patients treated as far back as 1987, prior to the acceptance of en bloc resection and chemotherapeutics as the treatment of choice, this series likely underestimates current survival rates.

Local recurrence was significantly higher in the EI cohort compared with the EA cohort. Contrary to other reports ${ }^{15}$ open versus needle biopsy did not have a statistically significant impact on local recurrence. Nevertheless, it is important to note that a significant difference in the type of biopsy performed between the EA and EI cohorts was found. As a result of the small sample size, the current study is underpowered to explore if the type of biopsy plays a significant role in patient outcome. Furthermore, of the patients with local recurrence, $59 \%$ died by the completion of the study. This concurs with previ- 


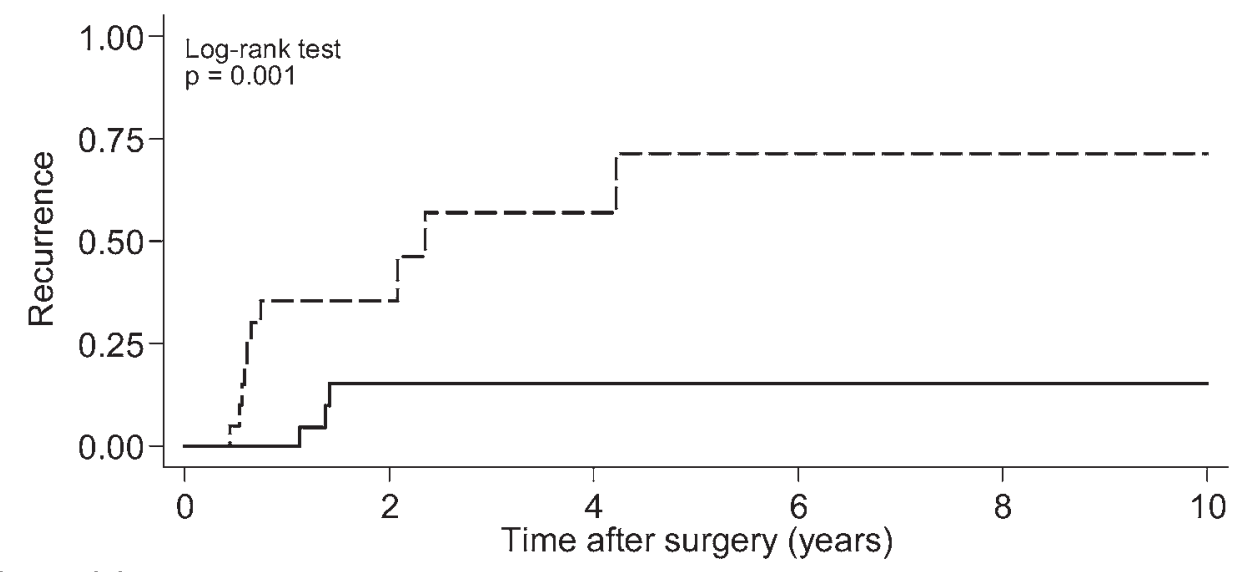

No. at risk

$\begin{array}{rrrrrrr}\text { El } & 24 & 6 & 3 & 2 & 1 & 1 \\ \text { EA } & 29 & 16 & 12 & 6 & 4 & 2\end{array}$

\section{Enneking Appropriate vs. Enneking Inappropriate

- EA - - - EI

FIG. 1. Kaplan-Meier analysis of time to first local recurrence following surgery in EA versus El patients. The number at risk indicates the number of patients included in the analysis. The median time to first local recurrence for El procedures is 2.3 years postoperation, while for EA procedures the median first time to local recurrence was not reached in this analysis.

ously published results, underscoring the importance of EA surgery and the high mortality associated with local recurrence. In a series of mixed sarcomas of the spine, positive resection margins resulted in a 5-fold increase in local recurrence, with a $92 \%$ mortality rate following local recurrence. ${ }^{57}$ These findings underscore the impact of tumor capsular disruption on local recurrence and survival. Unfortunately, due to the extreme technical challenges of en bloc resection in the spine and the morphology of the tumor itself, capsular disruption is not always avoidable if neurological elements are preserved. Thus, minimizing tumor spillage in planned capsular disruptions or sacrificing neurological anatomy may be necessary. While preoperative chemotherapy may help minimize the impact of controlled tumor transgression during surgery, this has not been formally studied.

Aggressive EA surgery points toward a significant survival advantage over EI surgery. In this study, median survival following EI resection was 3.7 years, while it was 6.8 years in the EA cohort. Historical data remain limited in spinal osteosarcoma cohorts. Schwab et al. published the largest case series of 17 patients with osteosarcoma of the

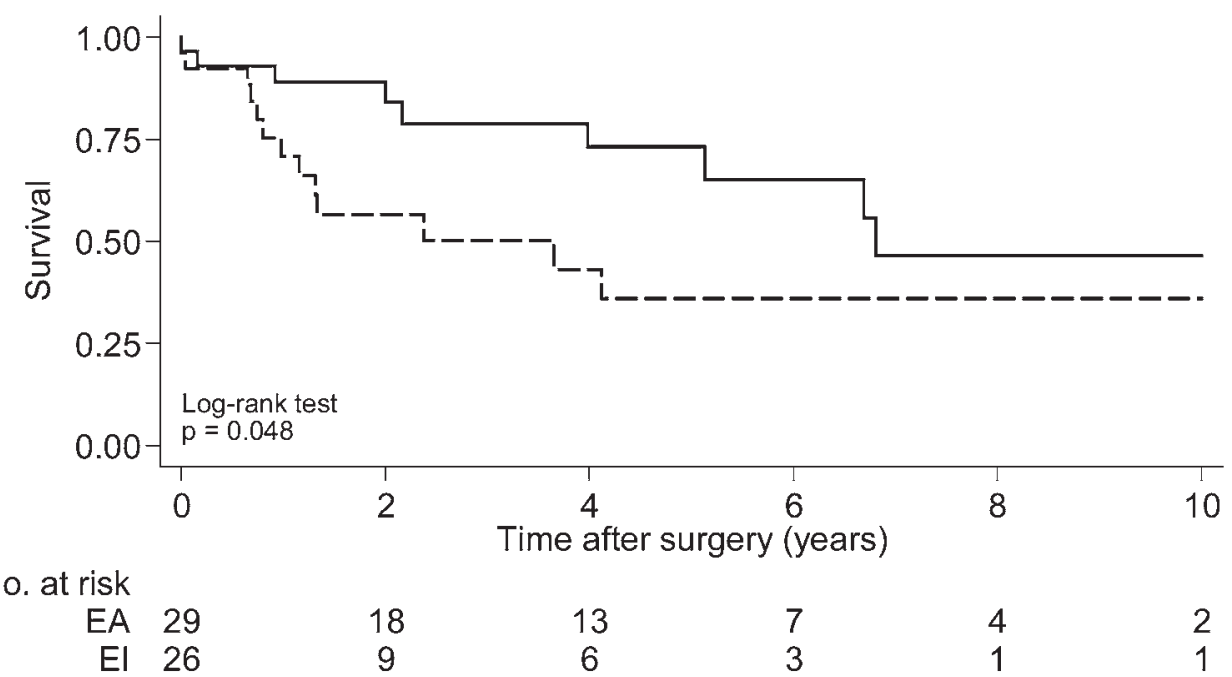

Enneking Appropriate vs. Enneking Inappropriate

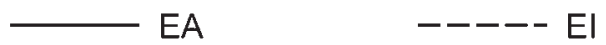

FIG. 2. Kaplan-Meier analysis of survival following surgery in EA versus El patients. The number at risk indicates the number of patients included in the analysis. The median survival for El procedures is 3.7 years postoperation, while for EA procedures the median survival is 6.8 years postoperatively. 
TABLE 5. Univariate results derived from the log-rank test used to evaluate the survival and incidence of local recurrence over a 10 -year period following resection

\begin{tabular}{|c|c|c|c|c|c|c|}
\hline \multirow[b]{2}{*}{ Variable } & \multicolumn{3}{|c|}{ Local Recurrence* } & \multicolumn{3}{|c|}{ Survival } \\
\hline & $\begin{array}{l}\text { No. of } \\
\text { Patients }\end{array}$ & $\begin{array}{c}\text { No. of Observed } \\
\text { Events (recurrences) }\end{array}$ & $\begin{array}{c}p \\
\text { Value }\end{array}$ & $\begin{array}{c}\text { No. of } \\
\text { Patients }\end{array}$ & $\begin{array}{l}\text { No. of Observed } \\
\text { Events (deaths) }\end{array}$ & $\mathrm{p}$ Value \\
\hline Age at surgery (yrs) & & & 0.600 & & & 0.882 \\
\hline$<25$ & 18 & 7 & & 18 & 7 & \\
\hline $25-44$ & 22 & 6 & & 23 & 9 & \\
\hline$\geq 45$ & 16 & 3 & & 17 & 8 & \\
\hline Previous spine tumor operation & & & 0.486 & & & 0.872 \\
\hline Yes & 15 & 5 & & 15 & 6 & \\
\hline No & 41 & 11 & & 43 & 18 & \\
\hline Biopsy & & & 0.118 & & & 0.584 \\
\hline Open & 11 & 6 & & 11 & 4 & \\
\hline CT-trocar & 29 & 7 & & 30 & 11 & \\
\hline Intraoperative & 7 & 1 & & 8 & 4 & \\
\hline Spine level & & & 0.813 & & & 0.226 \\
\hline Mobile & 41 & 13 & & 41 & 17 & \\
\hline Fixed & 15 & 3 & & 17 & 7 & \\
\hline No. of vertebral levels spanned by the tumor & & & 0.621 & & & 0.554 \\
\hline 1 & 10 & 2 & & 10 & 4 & \\
\hline $2-3$ & 30 & 10 & & 30 & 16 & \\
\hline$\geq 4$ & 16 & 4 & & 18 & 4 & \\
\hline Tumor vol ellipsoid body $\left(\mathrm{cm}^{3}\right) \dagger$ & & & 0.703 & & & 0.193 \\
\hline$<100$ & 24 & 8 & & 25 & 9 & \\
\hline$\geq 100$ & 26 & 5 & & 27 & 11 & \\
\hline Enneking appropriateness & & & 0.001 & & & 0.048 \\
\hline EA & 29 & 3 & & 29 & 9 & \\
\hline $\mathrm{El}$ & 24 & 10 & & 26 & 13 & \\
\hline Chemotherapy timing & & & 0.233 & & & 0.063 \\
\hline Preoperative & 19 & 5 & & 19 & 8 & \\
\hline Postoperative & 9 & 5 & & 9 & 5 & \\
\hline Both & 18 & 4 & & 19 & 4 & \\
\hline None & 10 & 2 & & 11 & 7 & \\
\hline
\end{tabular}

* Complete information is available for 56 of 58 patients.

$\dagger$ Tumor volume ellipsoid body $=\pi / 6 \times$ height $\times$ width $\times$ depth

mobile spine and demonstrated a survival advantage of en bloc resection (median survival 77.3 months) versus intralesional resection (median survival 16.8 months) ${ }^{50}$ that did not reach statistical significance. In a small series, the 5 patients with wide or marginal tumor resections had a statistically significant survival advantage over the 17 patients with intralesional or no surgery. ${ }^{44}$ Aggressive surgery was also supported in the study by DeLaney et al. that explored the utility of proton beam adjuvant therapy; however, this study was based on tumor volume, not margins, and thus does not obviate the need for EA surgery. ${ }^{19}$ In a mixed histology series of sarcomas, Groves et al. found that en bloc resection offered a significant survival advantage over intralesional resection. ${ }^{29}$ Although studies remain scant and limited due to small sample sizes, by using a systematic review format and consensus recommendations Sciubba et al. strongly recommend en bloc resection for local control and possible overall survival despite very low evidence. ${ }^{51}$ Specifically, they recommended that a multidisciplinary panel determine the feasibility of en bloc resection and that an experienced team perform this procedure. It should be noted, however, that the feasibility of en bloc resections is tumor dependent, as technical challenges and proximity to critical structures may make EA resections unfeasible or require the patient to accept significant impairment. Surgeons must use good judgment and patient preference when determining the surgical approach.

Neoadjuvant chemotherapy has become accepted as the standard treatment for osteogenic sarcoma of the spine. While the value of chemotherapy for spinal osteosarcoma has not been specifically evaluated, its value has been clearly demonstrated in extremity osteosarcoma with a biological rationale that is expected to be independent of primary tumor location. The current study is under- 
powered to detect an absolute benefit to chemotherapy, as 47 of 58 patients had chemotherapeutic treatment and the small comparison cohort makes analysis difficult. Nevertheless, it is important to note that significantly more EA-treated patients received neoadjuvant chemotherapy compared with EI-treated patients; thus, neoadjuvant chemotherapy may have a positive impact on overall outcome. Other spine studies, while also underpowered, have demonstrated a trend toward longer survival with neoadjuvant therapy. ${ }^{52,56}$ In one study in which patients were treated with high-dose methotrexate and Adriamycin, it was concluded that the preferred treatment for spinal osteosarcoma should include neoadjuvant therapy and at least a marginal resection to optimize outcome. ${ }^{44}$ Similarly, a study of 26 patients treated with multimodality therapy, including en bloc resection and neoadjuvant therapy, demonstrated better survival than historical controls ${ }^{48}$ such as those that predate the modern chemotherapeutic era.,52 Others have reported that patients undergoing neoadjuvant chemotherapy with contaminated surgical margins have avoided local and distant recurrences and theorized that this may be due to chemotherapeutic response. ${ }^{50}$ Although data focusing on the spine are scant, it is notable that the addition of chemotherapy to wide surgical excision in appendicular osteosarcoma has greatly increased survival. . $^{367,39,40,42,49,51,55,64}$ Importantly, a large study by Link et al. demonstrated that patients undergoing surgery only had a 2-year relapse-free survival rate of $17 \%$ versus $66 \%$ in the adjuvant chemotherapy group among 36 randomized patients, which was further supported by similar results in 77 patients who refused randomization. ${ }^{37}$ Gherlinzoni et al. further found that the incidence of local recurrence was related above all to adjuvant chemotherapy-induced tumor necrosis. ${ }^{28}$ Thus, it is reasonable to extrapolate the gains of aggressive surgery and neoadjuvant chemotherapy to the spine. Based on a combination of evidence involving appendicular and axial osteosarcoma studies, Sciubba et al. strongly recommended neoadjuvant chemotherapy based on a moderate level of evidence in their systematic review of osteosarcoma treatment. ${ }^{51}$

The role of adjuvant radiotherapy in the local treatment of spinal osteosarcoma remains incompletely defined at this time. While not traditionally considered a radiosensitive tumor, advanced radiation techniques (e.g., stereotactic radiotherapy delivery and proton beam therapy) may be able to deliver tumoricidal doses while not exceeding local neurological or adjacent organ toxicity constraints. ${ }^{11,18}$ At present, adjuvant radiotherapy remains investigational as a primary or adjuvant local control modality for spinal osteosarcoma.

Although this study is the largest cohort of spine osteogenic sarcomas in the literature and the first multicenter study of its kind, there are limitations. Spinal osteosarcoma is rare, and despite a multicenter ambispective design, the sample size is still small, making it challenging to explore the influence of neoadjuvant and adjuvant chemotherapies. Both the local recurrence and survival findings are also limited by the relatively short follow-up time for a tumor study. This probably biases toward the null hypothesis; however, longer follow-up with this now-established cohort would strengthen validity. Furthermore, terminol- ogy, pathological differentiators, and innovations in surgical and adjuvant therapy may not be reflected in this study based on its multicenter format and time frame for data collection. These limitations can only be reduced by a carefully designed, rigidly performed prospective study, which has been initiated by the AOSpine Knowledge Forum Tumor and involves several more centers. Research questions about EA and EI margins, planned transgressions, health-related quality of life, adjuvant and neoadjuvant treatment protocols, biopsy techniques, molecular and genetic phenotyping, and the prognosis of tumors, have been included.

\section{Conclusions}

Osteosarcoma is an aggressive tumor; however, EA surgical procedures significantly reduce local recurrence and increase survival. While these findings are significant, the differences in adjuvant chemotherapy, type of biopsy, and previous spine tumor operations between cohorts may bias these results. Therefore, further studies are needed to explore the effects of EA surgery and adjuvant and neoadjuvant chemotherapeutics, in addition to the type of biopsy performed, in spinal osteosarcoma patients.

\section{Acknowledgments}

We are grateful to the collaborating centers' local clinical research personnel and support staff for their active participation. We especially thank AOSpine's Clinical Investigation and Documentation unit for their assistance with the statistical analysis.

\section{References}

1. Barwick KW, Huvos AG, Smith J: Primary osteogenic sarcoma of the vertebral column: a clinicopathologic correlation of ten patients. Cancer 46:595-604, 1980

2. Bauer HC, Wedin R: Survival after surgery for spinal and extremity metastases. Prognostication in 241 patients. Acta Orthop Scand 66:143-146, 1995

3. Bielack SS, Wulff B, Delling G, Göbel U, Kotz R, Ritter J, et al: Osteosarcoma of the trunk treated by multimodal therapy: experience of the Cooperative Osteosarcoma study group (COSS). Med Pediatr Oncol 24:6-12, 1995

4. Bilsky MH, Boland PJ, Panageas KS, Woodruff JM, Brennan MF, Healey JH: Intralesional resection of primary and metastatic sarcoma involving the spine: outcome analysis of 59 patients. Neurosurgery 49:1277-1287, 2001

5. Borgoch E, English E, Perrin RG, Tator CH: Successful surgical decompression of spinal extradural metastases of liposarcoma. Spine (Phila Pa 1976) 8:228-235, 1983

6. Boriani S, Biagini R, De Iure F, Bertoni F, Malaguti MC, Di Fiore M, et al: En bloc resections of bone tumors of the thoracolumbar spine. A preliminary report on 29 patients. Spine (Phila Pa 1976) 21:1927-1931, 1996

7. Boriani S, Weinstein JN, Biagini R: Primary bone tumors of the spine. Terminology and surgical staging. Spine (Phila Pa 1976) 22:1036-1044, 1997

8. Brennan MF: Soft tissue sarcoma: advances in understanding and management. Surgeon 3:216-223, 2005

9. Cha C, Antonescu CR, Quan ML, Maru S, Brennan MF: Long-term results with resection of radiation-induced soft tissue sarcomas. Ann Surg 239:903-910, 2004

10. Chan P, Boriani S, Fourney DR, Biagini R, Dekutoski MB, Fehlings MG, et al: An assessment of the reliability of the Enneking and Weinstein-Boriani-Biagini classifications for 
staging of primary spinal tumors by the Spine Oncology Study Group. Spine (Phila Pa 1976) 34:384-391, 2009

11. Ciernik IF, Niemierko A, Harmon DC, Kobayashi W, Chen YL, Yock TI, et al: Proton-based radiotherapy for unresectable or incompletely resected osteosarcoma. Cancer 117:4522-4530, 2011

12. Clarke MJ, Dasenbrock H, Bydon A, Sciubba DM, McGirt MJ, Hsieh PC, et al: Posterior-only approach for en bloc sacrectomy: clinical outcomes in 36 consecutive patients. Neurosurgery 71:357-364, 2012

13. Clarke MJ, Hsu W, Suk I, McCarthy E, Black JH III, Sciubba DM, et al: Three-level en bloc spondylectomy for chordoma. Neurosurgery 68 (2 Suppl Operative):325-333, 2011

14. Clarke MJ, Mendel E, Vrionis FD: Primary spine tumors: diagnosis and treatment. Cancer Contr 21:114-123, 2014

15. Clarke MJ, Zadnick PL, Groves ML, Dasenbrock HH, Sciubba DM, Hsu W, et al: En block hemisacrectomy and internal hemipelvectomy via the posterior approach. J Neurosurg Spine 21:458-467, 2014

16. Cohen ZR, Fourney DR, Marco RA, Rhines LD, Gokaslan ZL: Total cervical spondylectomy for primary osteogenic sarcoma. Case report and description of operative technique. J Neurosurg 97 (3 Suppl):386-392, 2002

17. Conlon KC, Casper ES, Brennan MF: Primary gastrointestinal sarcomas: analysis of prognostic variables. Ann Surg Oncol 2:26-31, 1995

18. DeLaney TF, Liebsch NJ, Pedlow FX, Adams J, Dean S, Yeap BY, et al: Phase II study of high-dose photon/proton radiotherapy in the management of spine sarcomas. Int $\mathbf{J}$ Radiat Oncol Biol Phys 74:732-739, 2009

19. DeLaney TF, Park L, Goldberg SI, Hug EB, Liebsch NJ, Munzenrider JE, et al: Radiotherapy for local control of osteosarcoma. Int J Radiat Oncol Biol Phys 61:492-498, 2005

20. Dirix LY, Vermeulen P, De Wever I, Van Oosterom AT: Soft tissue sarcoma in adults. Curr Opin Oncol 9:348-359, 1997

21. Dreghorn CR, Newman RJ, Hardy GJ, Dickson RA: Primary tumors of the axial skeleton. Experience of the Leeds Regional Bone Tumor Registry. Spine (Phila Pa 1976) 15:137140,1990

22. Enneking WF: A system of staging musculoskeletal neoplasms. Clin Orthop Relat Res 204:9-24, 1986

23. Enneking WF, Spanier SS, Goodman MA: A system for the surgical staging of musculoskeletal sarcoma. Clin Orthop Relat Res 153:106-120, 1980

24. Farhood AI, Hajdu SI, Shiu MH, Strong EW: Soft tissue sarcomas of the head and neck in adults. Am J Surg 160:365369,1990

25. Fischgrund JS, Cantor JB, Samberg LC: Malignant degeneration of a vertebral osteochondroma with epidural tumor extension: a report of the case and review of the literature. J Spinal Disord 7:86-90, 1994

26. Fisher CG, Keynan O, Boyd MC, Dvorak MF: The surgical management of primary tumorsof the spine: initial results of an ongoing prospective cohort study. Spine (Phila Pa 1976) 30:1899-1908, 2005

27. Gandolfi A, Bordi C: Primary osteosarcoma of the cervical spine causing neurological symptoms. Surg Neurol 21:441444, 1984

28. Gherlinzoni F, Picci P, Bacci G, Campanacci D: Limb sparing versus amputation in osteosarcoma. Correlation between local control, surgical margins and tumor necrosis: Istituto Rizzoli experience. Ann Oncol 3 (Suppl 2):S23-S27, 1992

29. Groves ML, Zadnick PL, Kaloostian P, Sui J, Goodwin CR, Wolinsky JP, et al: Epidemiologic, functional, and oncologic outcome analysis of spinal sarcomas treated surgically at a single institution over 10 years. Spine J 15:110-114, 2015

30. Heslin MJ, Lewis JJ, Nadler E, Newman E, Woodruff JM, Casper ES, et al: Prognostic factors associated with long- term survival for retroperitoneal sarcoma: implications for management. J Clin Oncol 15:2832-2839, 1997

31. Hollenbeck ST, Grobmyer SR, Kent KC, Brennan MF: Surgical treatment and outcomes of patients with primary inferior vena cava leiomyosarcoma. J Am Coll Surg 197:575-579, 2003

32. Kelley SP, Ashford RU, Rao AS, Dickson RA: Primary bone tumours of the spine: a 42-year survey from the Leeds Regional Bone Tumour Registry. Eur Spine J 16:405-409, 2007

33. Kraus DH, Dubner S, Harrison LB, Strong EW, Hajdu SI, Kher U, et al: Prognostic factors for recurrence and survival in head and neck soft tissue sarcomas. Cancer 74:697-702, 1994

34. Laus M, Zappoli FA, Malaguti MC, Alfonso C: Intralesional surgery of primary tumors of the anterior cervical column. Chir Organi Mov 83:43-51, 1998

35. Lefebvre G, Renaud A, Rocourt N, Cortet B, Ceugnart L, Cotten A: Primary vertebral osteosarcoma: five cases. Joint Bone Spine 80:534-537, 2013

36. Link M, Goorin A, Horowitz M, Meyer WH, Belasco J, Baker A, et al: Adjuvant chemotherapy of high-grade osteosarcoma of the extremity: updated results of the Multi-Institutional Osteosarcoma Study. Clin Ortho Relat Res:8-14, 1991

37. Link MP, Goorin AM, Miser AW, Green AA, Pratt CB, Belasco JB, et al: The effect of adjuvant chemotherapy on relapse-free survival in patients with osteosarcoma of the extremity. N Engl J Med 314:1600-1606, 1986

38. Lo TH, van Rooij WJ, Teepen JL, Verhagen IT: Primary leiomyosarcoma of the spine. Neuroradiology 37:465-467, 1995

39. Mankin HJ, Hornicek FJ, Rosenberg AE, Harmon DC, Gebhardt MC: Survival data for 648 patients with osteosarcoma treated at one institution. Clin Orthop Relat Res 429:286291, 2004

40. Marcove RC, Miké V, Hajek JV, Levin AG, Hutter RV: Osteogenic sarcoma under the age of twenty-one. A review of one hundred and forty-five operative cases. J Bone Joint Surg Am 52:411-423, 1970

41. McCarter MD, Jaques DP, Brennan MF: Randomized clinical trials in soft tissue sarcoma. Surg Oncol Clin N Am 11:11-22, 2002

42. Meyers PA, Heller G, Healey J, Huvos A, Lane J, Marcove R, et al: Chemotherapy for nonmetastatic osteogenic sarcoma: the Memorial Sloan-Kettering experience. J Clin Oncol 10:5-15, 1992

43. Nishida J, Kato S, Shiraishi H, Ehara S, Sato T, Okada K, et al: Leiomyosarcoma of the lumbar spine: case report. Spine (Phila Pa 1976) 27:E42-E46, 2002

44. Ozaki T, Flege S, Liljenqvist U, Hillmann A, Delling G, Salzer-Kuntschik M, et al: Osteosarcoma of the spine: experience of the Cooperative Osteosarcoma Study Group. Cancer 94:1069-1077, 2002

45. Roy-Camille R, Saillant G, Bisserié M, Judet T, Hautefort E, Mamoudy P: [Total excision of thoracic vertebrae (author's transl).] Rev Chir Orthop Repar Appar Mot 67:421-430, $1981(\mathrm{Fr})$

46. Roy-Camille R, Saillant G, Mazel CH, Monpierre H: Total vertebrectomy as treatment of malignant tumors of the spine. Chir Organi Mov 75 (1 Suppl):94-96, 1990

47. Russo P, Brady MS, Conlon K, Hajdu SI, Fair WR, Herr HW, et al: Adult urological sarcoma. J Urol 147:1032-1037, 1992

48. Schoenfeld AJ, Hornicek FJ, Pedlow FX, Kobayashi W, Garcia RT, DeLaney TF, et al: Osteosarcoma of the spine: experience in 26 patients treated at the Massachusetts General Hospital. Spine J 10:708-714, 2010

49. Schwab JH, Antonescu CR, Athanasian EA, Boland PJ, Healey JH, Morris CD: A comparison of intramedullary and juxtacortical low-grade osteogenic sarcoma. Clin Orthop Relat Res 466:1318-1322, 2008 
50. Schwab J, Gasbarrini A, Bandiera S, Boriani L, Amendola L, Picci P, et al: Osteosarcoma of the mobile spine. Spine (Phila Pa 1976) 37:E381-E386, 2012

51. Sciubba DM, Okuno SH, Dekutoski MB, Gokaslan ZL: Ewing and osteogenic sarcoma: evidence for multidisciplinary management. Spine (Phila Pa 1976) 34 (22 Suppl):S58S68, 2009

52. Shives TC, Dahlin DC, Sim FH, Pritchard DJ, Earle JD: Osteosarcoma of the spine. J Bone Joint Surg Am 68:660 668,1986

53. Singer S, Antonescu CR, Riedel E, Brennan MF: Histologic subtype and margin of resection predict pattern of recurrence and survival for retroperitoneal liposarcoma. Ann Surg 238:358-371, 2003

54. Stojadinovic A, Yeh A, Brennan MF: Completely resected recurrent soft tissue sarcoma: primary anatomic site governs outcomes. J Am Coll Surg 194:436-447, 2002

55. Sundaresan N, Rosen G, Boriani S: Primary malignant tumors of the spine. Orthop Clin North Am 40:21-36, v, 2009

56. Sundaresan N, Rosen G, Huvos AG, Krol G: Combined treatment of osteosarcoma of the spine. Neurosurgery 23:714719,1988

57. Talac R, Yaszemski MJ, Currier BL, Fuchs B, Dekutoski $\mathrm{MB}, \mathrm{Kim} \mathrm{CW}$, et al: Relationship between surgical margins and local recurrence in sarcomas of the spine. Clin Orthop Relat Res 397:127-132, 2002

58. Tasdemiroglu E, Bagatur E, Ayan I, Darendeliler E, Patchell RA: Primary spinal column sarcomas. Acta Neurochir (Wien) 138:1261-1266, 1996

59. Tigani D, Pignatti G, Picci P, Savini R, Campanacci M: Vertebral osteosarcoma. Ital J Orthop Traumatol 14:5-13, 1988

60. Tomita K, Kawahara N, Baba H, Tsuchiya H, Fujita T, Toribatake Y: Total en bloc spondylectomy. A new surgical technique for primary malignant vertebral tumors. Spine (Phila Pa 1976) 22:324-333, 1997

61. Tomita K, Toribatake Y, Kawahara N, Ohnari H, Kose H: Total en bloc spondylectomy and circumspinal decompression for solitary spinal metastasis. Paraplegia 32:36-46, 1994

62. Weinstein JN, McLain RF: Primary tumors of the spine. Spine (Phila Pa 1976) 12:843-851, 1987

63. Weitz J, Antonescu CR, Brennan MF: Localized extremity soft tissue sarcoma: improved knowledge with unchanged survival over time. J Clin Oncol 21:2719-2725, 2003

64. Wilkins RM, Cullen JW, Odom L, Jamroz BA, Cullen PM, Fink K, et al: Superior survival in treatment of primary nonmetastatic pediatric osteosarcoma of the extremity. Ann Surg Oncol 10:498-507, 2003

65. Yao KC, Boriani S, Gokaslan ZL, Sundaresan N: En bloc spondylectomy for spinal metastases: a review of techniques. Neurosurg Focus 15(5):E6, 2003

\section{Disclosures}

Dr. Rhines is a consultant for Stryker and Globus. Dr. Sciubba is a consultant for Medtronic and has a financial relationship with DePuy Synthes. Dr. Fisher is a consultant for Medtronic and NuVasive, and has a financial relationship with Medtronic. Dr. Rose is a consultant for K2M. Dr. Germscheid has financial relationships with AOSpine. Dr. Chou is a consultant for Medtronic, Globus, and Orthofix.

This study was organized and funded by AOSpine International through the AOSpine Knowledge Forum Tumor, a pathologyfocused working group of up to 10 international spine experts acting on behalf of AOSpine in the domain of scientific expertise. AOSpine is a clinical division of the AO Foundation - an independent, medically guided, nonprofit organization. Each forum consists of a steering committee of up to 10 international spine experts who meet on a regular basis to discuss research, assess the best evidence for current practices, and formulate clinical trials to advance spine care worldwide. Study support was provided directly through AOSpine's Research department and AO's Clinical Investigation and Documentation unit.

\section{Author Contributions}

Conception and design: Dekutoski, Rose, Luzzati, Rhines, Varga, Fisher, Chou, Fehlings, Reynolds, Williams, Quraishi, Sciubba, Gokaslan, Boriani. Acquisition of data: Dekutoski, Luzzati, Rhines, Varga, Fisher, Chou, Fehlings, Reynolds, Williams, Quraishi, Sciubba, Gokaslan, Boriani. Analysis and interpretation of data: Clarke, Luzzati, Rhines, Fisher, Fehlings, Germscheid, Gokaslan, Boriani. Drafting the article: Clarke, Varga, Fisher, Germscheid, Sciubba, Boriani. Critically revising the article: all authors. Reviewed submitted version of manuscript: all authors. Approved the final version of the manuscript on behalf of all authors: Clarke. Statistical analysis: Clarke, Germscheid. Administrative/technical/material support: Germscheid. Study supervision: Rhines, Varga, Fisher, Gokaslan, Boriani.

\section{Supplemental Information \\ Previous Presentations}

Portions of this paper were presented at the 2015 Global Spine Congress, Buenos Aires, Argentina, and the submitted congress abstract was published in a special Global Spine Congress supplement within the Global Spine Journal (Clarke et al. Global Spine J 2015; 05-A110, 2015). The title and modified abstract are included with permission from Thieme Medical Publishers.

\section{Correspondence}

Michelle J. Clarke, Department of Neurologic Surgery, Go8S, Mayo Clinic, 200 First St. SW, Rochester, MN 55906. email: clarke.michelle@mayo.edu. 